Central European Journal of Energetic Materials, 2016, 13(1), 247-260

ISSN 1733-7178

e-ISSN 2353-1843

\title{
Mixtures of Phase-stabilized Ammonium Nitrate and Tetrazoles as New Gas-generating Agent Compositions
}

\author{
Kazuo HASUE $^{1 *}$, Kazuya YOSHITAKE ${ }^{2}$, Makoto MATSUKAWA ${ }^{3}$ \\ ${ }^{1}$ Department of Applied Chemistry, School of Applied Sciences, \\ National Defense Academy \\ 1-10-20, Hashirimizu, Yokosuka, Kanagawa 239-8686, Japan \\ ${ }^{2}$ Test and Evaluation Command, Japan Ground Self-Defense \\ Force, 481-27, Subashiri, Oyama, Shizuoka 410-1431, Japan \\ ${ }^{3}$ The Kure Ammunition Storehouse and Maintenance Depot, \\ Japan Maritime Self-Defense Force, \\ Kirikushi, Etajima, Hiroshima 737-2111, Japan \\ *E-mail: khasue@hotmail.com
}

\begin{abstract}
New gas-generating agents for air bags have been investigated. Ammonium nitrate does not give off harmful gases nor leave solid residues but goes through contraction and expansion during a series of phase transitions that cause structural damage within the material. In this study, potassium-nitratephase-stabilized ammonium nitrate (PSAN) was prepared by a nonhazardous aqueous method. Ammonium nitrate-based propellants have low burning rates. Tetrazoles were selected as they have a large heat of formation and can be used as fuel components for ammonium nitrate-based gas-generating agents. A number of different experiments were conducted on the novel tetrazole/PSAN mixtures in order to evaluate their application as gas-generating agents.
\end{abstract}

Keywords: potassium-nitrate-phase-stabilized ammonium nitrate(V), tetrazoles, gas-generating agents, burning rate, $4 \mathrm{~L}$ tank test

\section{Introduction}

Air bags are vehicle safety devices that are designed to inflate rapidly during an automobile collision. Their purpose is to cushion the occupants during a crash 
and to protect their bodies from serious injuries. After the onset of a crash, signals from the impact sensors are fed into the air bag control unit that triggers the ignition of a gas-generating agent to rapidly inflate a fabric bag in $25-50 \mathrm{~ms}$. Once an air bag has been deployed, deflation begins within $80-100 \mathrm{~ms}$ as the gas escapes through vents in the fabric. Deployment is frequently accompanied by the release of dust-like particles and gases in the vehicle's interior.

Some of the desirable characteristics of gas-generating agents for air bags are as follows [1].

(1) The basic burning characteristics of gas-generating agents are evaluated by means of a chimney-type strand burner and a $60 \mathrm{~L}$ tank. Gas-generating agents generally require a burning rate of at least $10 \mathrm{~mm} \cdot \mathrm{s}^{-1}$ or more at $7 \mathrm{MPa}$ because compositions with a burning rate less than this do not ignite reliably and often result in "no-fires" within the inflator [2]. Burning rates of energetic materials generally follow Vieille's law, given by $r=a \cdot P^{n}$, where $a$ is a constant dependent on the chemical composition and the initial propellant temperature, and $n$ is the pressure exponent of the burning rate [3]. The pressure exponent should be as close to zero as possible. As $n$ increases, a very small change in pressure will result in a large change in the burning rate, which could result in ballistic variability or over-pressurization. Therefore, for automotive air bag applications, $n$ of approximately 0.30 or less is desirable over the operating pressure of the inflator [4].

(2) It is preferable that the gas-generating agent produces no harmful gases, because air bags release the combustion gases inside the vehicle after their deployment in order to maintain the driver's view [1].

(3) It is desirable that the gaseous products are more than $90 \%$ of the total product mass, and that solid products are $10 \%$ or less of the total product mass [2]. The number of moles of generated gas is adjusted to more than $2.70 \mathrm{~mol}$ per $100 \mathrm{~g}$ of gas-generating agent [5]. The primary gaseous products for carbon and nitrogen in the gas-generating agent are $\mathrm{CO}_{2}$ and $\mathrm{N}_{2}$, respectively. When produced, $\mathrm{H}_{2} \mathrm{O}$ is also considered as a gas in the calculation of these values because it is usually fed to the air bag in the form of a gas [5]. When the produced $\mathrm{H}_{2} \mathrm{O}$ content increases, the deployment temperature and the quantity of steam decrease and the pressure in the air bag tends to drop. Therefore, it is preferable that the mol.\% of $\mathrm{H}_{2} \mathrm{O}$ from a gas-generating agent is lower than 50 [6].

(4) The gas-generating agent must be designed so that the temperature of the generated gas is as low as possible to reduce damage to the air bag and to eliminate burn injuries for the vehicle occupants. It is preferable that the calorific value per gram of the gas-generating agent is no more than $4000 \mathrm{~J} \mathrm{[5]} \mathrm{and} \mathrm{the}$ adiabatic flame temperature $\left(T_{\mathrm{f}}\right)$ of the gas-generating agent is $2273 \mathrm{~K}$ or less [7]. 
A gas generator that uses a gas-generating agent with a large calorific value requires a large amount of coolant. Consequently, it becomes difficult to realize the reduction in size and weight of the gas generator. The ideal calorific value per mole of generated gas is in the range of 95 to $105 \mathrm{~kJ}$ [5]. If the temperature of the generated gas is too low, a large amount of gas-generating agent is needed to obtain the required gas volume for inflating the air bag.

(5) It is necessary to avoid material that may cause detonation or spontaneous combustion during the manufacturing process [1].

Ammonium nitrate(V) (AN) has attracted attention over the years as an oxidizer for environmentally friendly and clean gas-generating systems because it does not give off harmful gases or leave solid residues. These advantages generally fulfill the strict requirements imposed on gas-generating agents for vehicle air bag systems. Additionally, $\mathrm{AN}$ is one of the cheapest and most easily available compounds for producing gas-generating agents. However, $\mathrm{AN}$ has the disadvantages of being hygroscopic (which becomes a problem during manufacture and storage) and of undergoing contraction and expansion during a series of phase transitions [8]. The phase transformation around room temperature results in crack formation in the propellant grain. Phase stabilization of AN has been achieved using additives such as potassium nitrate(V) $(\mathrm{KN})$ [8$11], \mathrm{CuO}[8,12,13], \mathrm{KF}[8,14]$, and various organic compounds [15].

In this study, phase-stabilized ammonium nitrate(V) was prepared by a nonhazardous aqueous method. It was reported that by adding $5 \mathrm{wt} . \%$ of $\mathrm{KN}$ to $\mathrm{AN}$, the transition temperature of AN near room temperature disappeared [16]. The composition of the solids crystallized from an AN-KN solution at approximately $363 \mathrm{~K}$ was reported to be almost the same as that of the solution [10]. Accordingly, AN-KN solutions were evaporated to dryness at $363 \mathrm{~K}$ and then ground to obtain phase-stabilized ammonium nitrate containing $5 \mathrm{wt} . \%$ of KN (PSAN).

AN propellants burn very slowly compared to ammonium-perchloratebased systems. The low burning rate of AN propellants can be attributed to the slower reaction kinetics of the nitrogen oxides produced from AN and the lower enthalpy of combustion of AN with fuels. As a result, the gas phase flame in AN propellants is colder and further from the condensed surface resulting in reduced heat feedback and a lower burning rate [8].

AN-based gas-generating agents prepared by mixing with organic fuels have poor combustion reactivity compared to some metal perchlorate [17-19] or nitrate mixtures [20-22].

Tetrazoles are expected to be suitable as safe, easy-to-handle gas-generating agents [23]. Tetrazoles with a high heat of formation [24] can be used as a fuel component to improve the combustability of AN-based gas-generating agents. 
It has been reported that aminoguanidinium 5,5'-azobis-1H-tetrazolate (AGAT) [25-27] and 1H-tetrazole (1HT) $[28,29]$ can be used as a fuel to mix with AN.

We have previously investigated gas-generating agents that utilize PSAN and 1HT [16] or bis(1H-tetrazolyl)amine ammonium salt [30]. In the present study, commercially available energetic tetrazoles such as AGAT, 5-amino-1H-tetrazole (5-ATZ), 5-methyl-1H-tetrazole (M5T), and di-ammonia-5,5-bi-tetrazolate $\left(\mathrm{BHT} \cdot 2 \mathrm{NH}_{3}\right)$ were examined as fuels to mix with PSAN.

\section{Materials and Methods}

\subsection{Materials}

Figure 1 shows the structures of AGAT, BHT $2 \mathrm{NH}_{3}$, M5T, and 5-ATZ. To obtain PSAN, AN (190 g) and KN (10 g) were dissolved in a small amount of water; the solution was heated to allow the chemicals to dissolve. The solution was placed in a thermostatic oven at $363 \mathrm{~K}$ until completely dried. PSAN and each tetrazole (Toyo Kasei Kogyo Co., Ltd.) were milled with a vibration ball mill, sieved, and then dried in a vacuum dryer. The particle sizes of PSAN and each tetrazole were in the range $75-150 \mu \mathrm{m}$. Each tetrazole was mixed with PSAN at the stoichiometric ratios shown in Table 1. For the $4 \mathrm{~L}$ tank test, guanidinium nitrate $(\mathrm{GN})$, strontium nitrate $(\mathrm{SrN})$, and basic copper nitrate $(\mathrm{BCN})$ were mixed in the ratios 56.05:19.45:24.50 (w/w) respectively.<smiles>N=C(N)NN</smiles>

(a)<smiles>Nc1nnc(-c2nnn[nH]2)[nH]1</smiles>

(b)<smiles>Cc1nnn[nH]1</smiles>

(c)<smiles>Nc1nnn[nH]1</smiles>

(d)

Figure 1. Structures of the tetrazoles used in this study: (a) AGAT, (b) BHT·2 $\mathrm{NH}_{3}$, (c) M5T, (d) 5-ATZ. 


\subsection{Burning rate test}

$1.5 \mathrm{~g}$ quantities of the stoichiometric tetrazole/PSAN mixtures were uniaxially pressed at approximately $300 \mathrm{MPa}$ for $3 \mathrm{~min}$ to form cylindrical pellets (diameter $10 \mathrm{~mm}$, thickness $11 \mathrm{~mm}$ ). The side of the cylindrical pellet was coated with epoxy resin to ensure cigarette-type burning. The combustion tests were performed using a pressure- and temperature-controlled chimney-type strand burner with an optical window (TDK-15011, Tohata Denshi Co. Ltd.), under $\mathrm{N}_{2}$ atmosphere in the range 1-10 MPa. A schematic diagram of the burner is shown in Figure 2. The initial temperature was set to $296 \mathrm{~K}$. Ignition of the pellet was carried out with an electrically heated Nichrome wire (diameter $0.6 \mathrm{~mm}$ ) by means of a regulated DC power supply. The pressure in the chamber was measured with a pressure sensor after amplification through a signal amplifier; the data were recorded using a digital data recorder. From the acquired pressure-time data, as shown schematically in Figure 3, the burning rates $(r)$ were deduced from the duration of the recorded pressure increase. The pressure began to increase as soon as the sample started to burn and stopped increasing when combustion ceased. The average internal pressure $(P)$ was calculated by averaging the pressures at the start and end of burning. All measurements were conducted once at each pressure.

Strain gauge pressure transducer

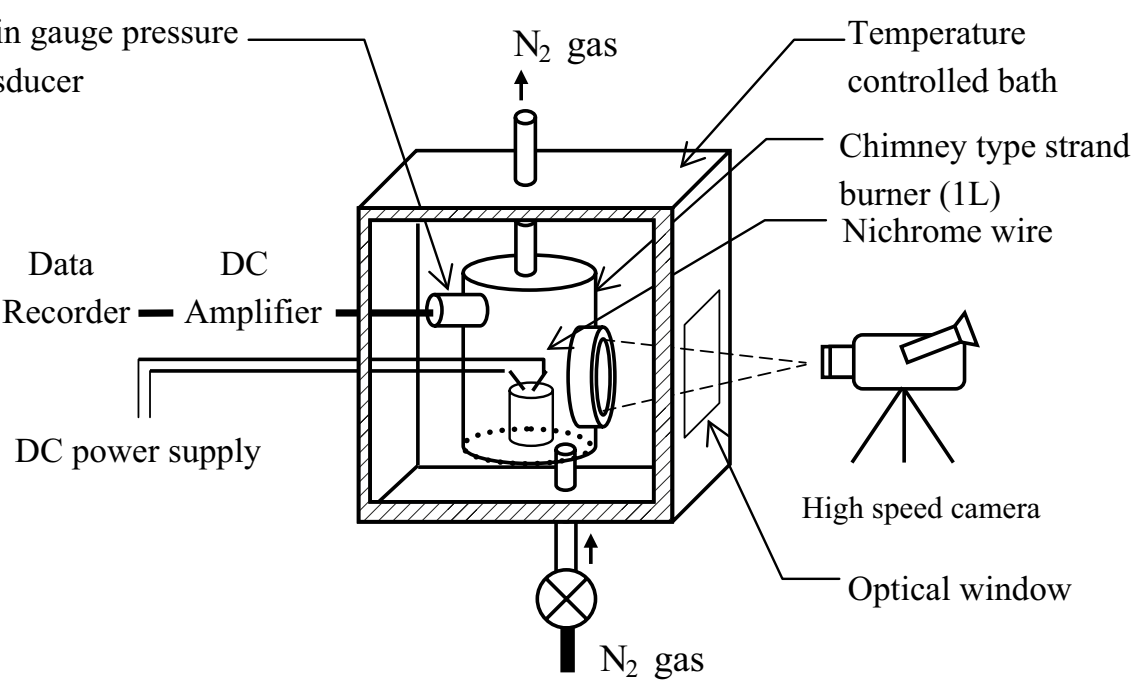

Figure 2. Schematic diagram of the pressure and temperature controlled chimney type strand burner (1L) with optical window. 


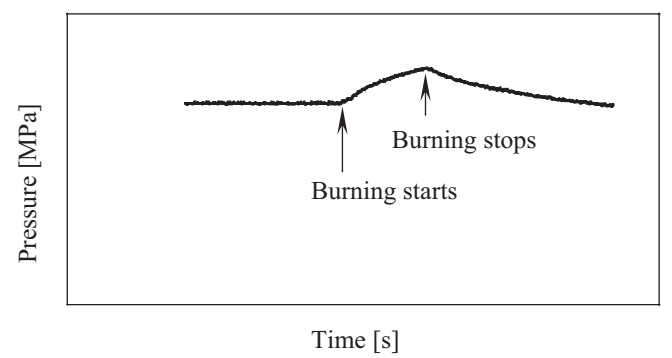

Figure 3. Schematic diagram of the pressure-time history from the burning rate measurements.

\subsection{L tank test}

The gas generation ability (which is generally measured by a $60 \mathrm{~L}$ tank test) was investigated using a $4 \mathrm{~L}$ tank test in this study. $4 \mathrm{~g}$ of the dried mixture was uniaxially pressed at approximately $200 \mathrm{MPa}$ for $3 \mathrm{~min}$ to form a cylindrical pellet (diameter $14.7 \mathrm{~mm}$, thickness $13.5-14.5 \mathrm{~mm}$ ).

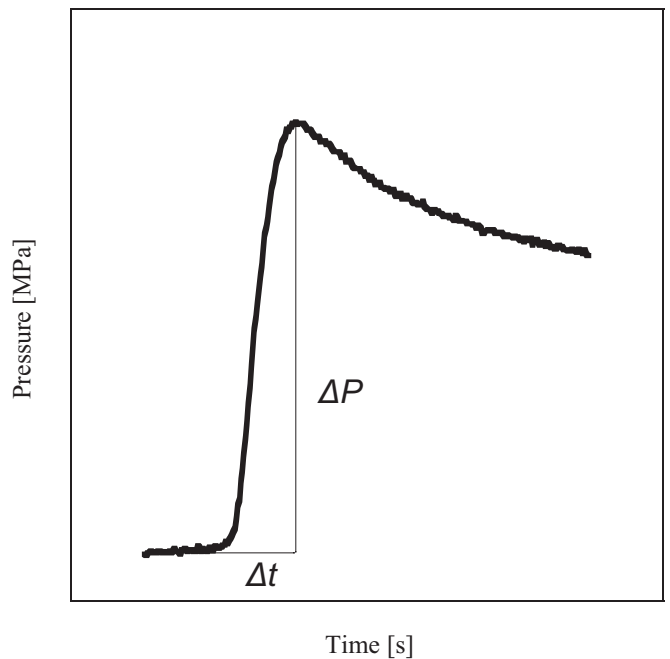

Figure 4. Schematic diagram of a $4 \mathrm{~L}$ tank test.

The pellet was uniformly coated with epoxy resin to achieve cigarette-type burning. The $4 \mathrm{~L}$ chimney-type strand burner (SCTA-50, Kyowa Giken Co., Ltd.) that had been used for the burning rate measurements was also used for these experiments with no modification other than closure of the gas flow exit. The $4 \mathrm{~L}$ tank tests were conducted at an initial temperature of $296 \mathrm{~K}$ and an initial pressure of $2 \mathrm{MPa}$. Ignition of the top surface of the sample was achieved using 
an electrically heated Nichrome wire. The internal pressure of the vessel was monitored using a pressure transducer, and after signal amplification (through a signal conditioner), the signal was recorded on a digital data recorder. From the acquired pressure-time data (Figure 4), $\Delta P$ (which is the net pressure increase between the initial pressure and maximum pressure) and $\Delta t$ (which is the time from the onset of pressure increase to when the pressure reaches its maximum), were calculated to determine the rate of pressure increase $(\Delta P / \Delta t)$.

\subsection{Chemical equilibrium calculations}

Chemical equilibrium calculations were conducted using the Fraunhofer-Institute für Chemische Technologie Thermodynamic Code (Ver. 23.09.96) [31].

\subsection{Sensitivity}

The impact sensitivity measurements of the mixtures were carried out according to the regulations of the Industrial Explosives Society [32]. The tin foil dish with $10-12 \mathrm{~mm}^{3}$ of the sample was placed between the two cylindrical steel rollers. The test was carried out at suitable drop height of 5, 10, 15, 20, 30, 40, and $50 \mathrm{~cm}$ (impact energy 4.9 to $49 \mathrm{~J}$ ) and observed whether or not there was an explosion. The limiting impact energy was defined as the lowest impact energy at which the result "explosion" was obtained from at least one out of six trials.

The friction sensitivity measurements of the mixtures were carried out by according to the regulations of the Industrial Explosives Society [32]. About $10 \mathrm{~mm}^{3}$ of the sample was placed on a rough ceramic plate and a force was loaded on the sample through a stationary ceramic pin, in contact with the plate. The plate was motor-driven through a complete cycle pass beneath the pin. The loading arm was loaded with nine different load weights in different notches enabled one to vary the loading force from 0.5 up to $353.0 \mathrm{~N}$. The friction sensitiveness was measured in terms of the limiting load. The limiting load was defined as the lowest load at which the result "explosion" was obtained from at least one out of six trials.

\section{Results and Discussion}

\subsection{Burning rate}

The results of the burning rate test for each tetrazole/PSAN mixture at $296 \mathrm{~K}$ are presented in Figure 5. It was confirmed that the burning rates of the mixtures followed Vieille's law. 


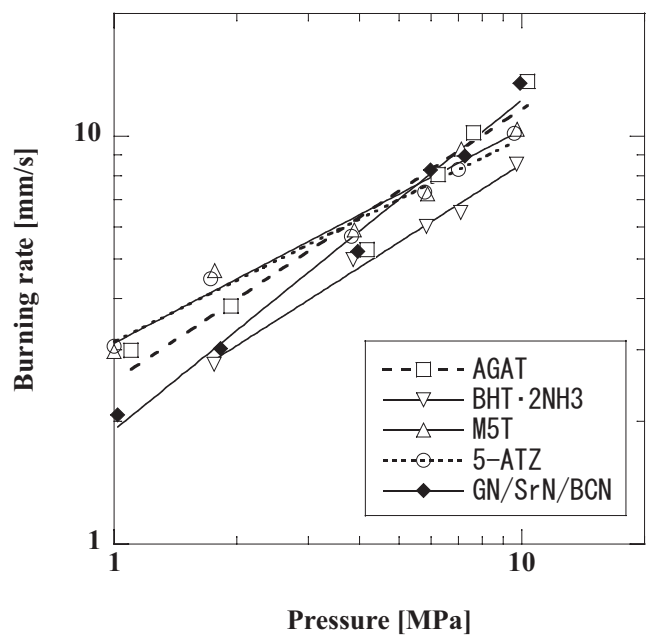

Figure 5. Burning rate for each tetrazole/PSAN mixture and the $\mathrm{GN} / \mathrm{SrN} / \mathrm{BCN}$ mixture.

The $a$ and $n$ values of each mixture are shown Table 1, and the burning rates of each mixture (except for BHT-2 $\mathrm{NH}_{3} / \mathrm{PSAN}$ ) at $7 \mathrm{MPa}$ were close to that of $\mathrm{GN} / \mathrm{SrN} / \mathrm{BCN}\left(9.2 \mathrm{~mm} \cdot \mathrm{s}^{-1}\right)$ but lower than the desirable rate of $10 \mathrm{~mm} \cdot \mathrm{s}^{-1}$ [2]. The burning rate of the $\mathrm{BHT} \cdot 2 \mathrm{NH}_{3} / \mathrm{PSAN}$ mixture at $7 \mathrm{MPa}$ was approximately $7 \mathrm{~mm} \cdot \mathrm{s}^{-1}$. The burning rate of each mixture can be improved by adding metallic oxides such as $\mathrm{SrN}$ [33]. Each mixture's $n$ value was larger than the preferred value of $0.3[4]$.

Table 1. Values of $a$ and $n$ for each tetrazole/PSAN mixture

\begin{tabular}{|c|c|c|c|c|}
\hline Mixture & $\begin{array}{c}\text { Mixing ratio } \\
{[\mathrm{wt.} \%]}\end{array}$ & $\begin{array}{c}a \\
{\left[\mathrm{~mm} \cdot \mathrm{s}^{-1} \cdot \mathrm{MPa}^{-1}\right]}\end{array}$ & $\begin{array}{c}n \\
{[-]}\end{array}$ & $\begin{array}{c}\text { Burning rate } \\
\text { at 7MPa } \\
{\left[\mathrm{mm} \cdot \mathrm{s}^{-1}\right]}\end{array}$ \\
\hline $\mathrm{AGAT} / \mathrm{PSAN}$ & $21.54 / 78.46$ & 2.51 & 0.667 & 9.20 \\
\hline $\mathrm{BHT} \cdot 2 \mathrm{NH}_{3} / \mathrm{PSAN}$ & $22.00 / 78.00$ & 1.97 & 0.637 & 6.81 \\
\hline $\mathrm{M}$ TT/PSAN & $15.52 / 84.48$ & 3.11 & 0.523 & 8.60 \\
\hline 5-ATZ/PSAN & $24.16 / 75.84$ & 3.13 & 0.499 & 8.68 \\
\hline GN/SrN/BCN & $56.05 / 19.45 / 24.50$ & 1.91 & 0.809 & 9.20 \\
\hline
\end{tabular}

SrN: Strontium nitrate, GN: Guanidinium nitrate, BCN: Copper nitrate basic. 


\subsection{L tank test}

The results for the $4 \mathrm{~L}$ tank tests are shown in Figure 6 and Table 2. Each sample was ignited and burned completely (except for M5T/PSAN). The rate of pressure increase $(\Delta P / \Delta t)$ for 5-ATZ/PSAN was $0.18 \mathrm{MPa} \cdot \mathrm{s}^{-1}$, which is larger than that for the $\mathrm{GN} / \mathrm{SrN} / \mathrm{BCN}$ mixture $\left(0.16 \mathrm{MPa} \cdot \mathrm{s}^{-1}\right)$. However, AGAT/PSAN and $\mathrm{BHT} \cdot 2 \mathrm{NH}_{3} / \mathrm{PSAN}$ showed smaller values than that for $\mathrm{GN} / \mathrm{SrN} / \mathrm{BCN}$. The net pressure increase $\Delta P$ of each mixture was larger than that for $\mathrm{GN} / \mathrm{SrN} / \mathrm{BCN}$. It was found that the tank test results for each mixture (except for M5T/PSAN) were generally acceptable for a practical gas-generating agent.

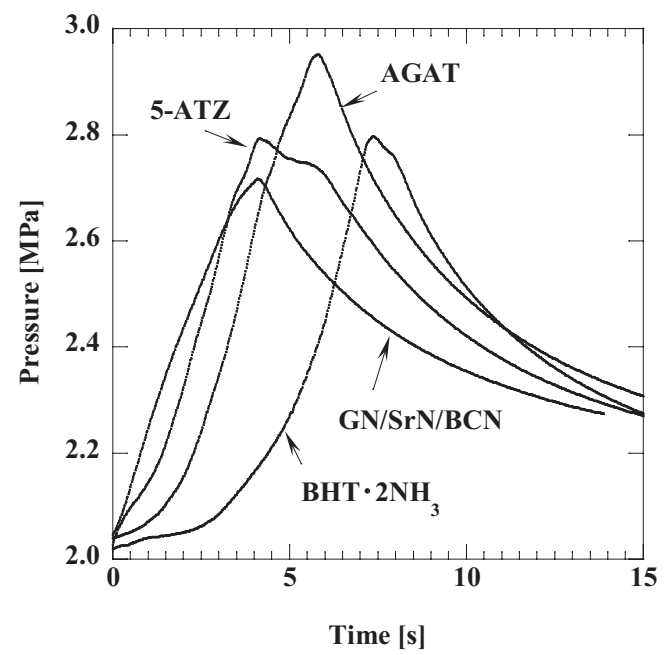

Figure 6. Pressure-time histories of each tetrazole/PSAN mixture and the GN/ $\mathrm{SrN} / \mathrm{BCN}$ mixture from the $4 \mathrm{~L}$ tank test.

Table 2. Gas generation ability for the mixtures

\begin{tabular}{|l|c|c|c|c|c|c|}
\hline \multicolumn{1}{|c|}{ Mixture } & $\begin{array}{c}\text { Mixing ratio } \\
{[\mathrm{wt} . \%]}\end{array}$ & $\begin{array}{c}\text { Starting } \\
\text { pressure } \\
{[\mathrm{MPa}]}\end{array}$ & $\begin{array}{c}\text { Maximum } \\
\text { pressure } \\
{[\mathrm{MPa}]}\end{array}$ & $\begin{array}{c}\text { Pressure } \\
\text { increase } \\
\Delta P \\
{[\mathrm{MPa}]}\end{array}$ & $\begin{array}{c}\text { Elapsed } \\
\text { time } \\
\Delta t \\
{[\mathrm{~s}]}\end{array}$ & $\begin{array}{c}\text { Rate of } \\
\text { pressure } \\
\text { increase } \\
\Delta P / \Delta t \\
{\left[\mathrm{MPa} \cdot \mathrm{s}^{-1}\right]}\end{array}$ \\
\hline $\begin{array}{l}\mathrm{AGAT} / \mathrm{PSAN} \\
\mathrm{BHT} \cdot 2 \mathrm{NH}_{3} /\end{array}$ & $21.54 / 78.46$ & 2.04 & 2.95 & 0.91 & 5.82 & 0.16 \\
\hline PSAN & $22.00 / 78.00$ & 2.02 & 2.80 & 0.78 & 7.38 & 0.11 \\
\hline $\mathrm{M} 5 \mathrm{~T} / \mathrm{PSAN}$ & $15.52 / 84.48$ & - & - & - & - & - \\
\hline 5-ATZ/PSAN & $24.16 / 75.84$ & 2.03 & 2.79 & 0.76 & 4.16 & 0.18 \\
\hline GN/SrN/BCN & $56.05 / 19.45 / 24.50$ & 2.05 & 2.72 & 0.67 & 4.10 & 0.16 \\
\hline
\end{tabular}

-: not available 


\subsection{Chemical equilibrium calculations}

Chemical equilibrium calculations were conducted to obtain the mol.\% and/or wt.\%, the total amount of gases generated, the heat of explosion, and $T_{\mathrm{f}}$ for each mixture (Table 3).

Table 3. Results of chemical equilibrium calculations for the tetrazole/PSAN mixtures

\begin{tabular}{|c|c|c|c|c|c|c|}
\hline \multicolumn{2}{|c|}{ Mixture } & $\begin{array}{l}\text { Desirable } \\
\text { values }\end{array}$ & $\begin{array}{l}\text { AGAT/ } \\
\text { PSAN }\end{array}$ & $\begin{array}{l}\mathrm{BHT} \cdot 2 \mathrm{NH}_{3} / \\
\text { PSAN }\end{array}$ & $\begin{array}{l}\text { M5T/ } \\
\text { PSAN }\end{array}$ & $\begin{array}{l}5-\mathrm{ATZ} / \\
\text { PSAN }\end{array}$ \\
\hline \multicolumn{2}{|c|}{$\begin{array}{l}\text { Mixing ratio } \\
\text { Tetrazole/PSAN, [wt.\%] }\end{array}$} & & $\begin{array}{l}21.54 / \\
78.46\end{array}$ & $22.00 / 78.00$ & $\begin{array}{l}15.52 / \\
84.48\end{array}$ & $\begin{array}{l}24.16 / \\
75.84\end{array}$ \\
\hline \multicolumn{2}{|c|}{$\begin{array}{l}\text { Adiabatic flame } \\
\text { temperature, }[\mathrm{K}]\end{array}$} & $\leqq 2273[7]$ & $\begin{array}{c}2850 \\
(2834.5)\end{array}$ & $\begin{array}{c}2847 \\
(2832.2)\end{array}$ & $\begin{array}{c}2862 \\
(2847.9)\end{array}$ & $\begin{array}{c}2885 \\
(2874.2)\end{array}$ \\
\hline \multicolumn{2}{|c|}{$\begin{array}{l}\text { Calorific value per gram } \\
\text { of gas-generating agent } \\
\text { (water gaseous) }\left[\mathrm{J} \cdot \mathrm{g}^{-1}\right]\end{array}$} & $\geqq 4000[5]$ & $\begin{array}{c}3799 \\
(3795)\end{array}$ & $\begin{array}{c}3798 \\
(3794.1)\end{array}$ & $\begin{array}{c}3884 \\
(3885)\end{array}$ & $\begin{array}{c}3815 \\
(3812)\end{array}$ \\
\hline \multirow{5}{*}{$\begin{array}{l}\text { Generated } \\
\text { products } \\
\text { [mol.\%] }\end{array}$} & $\mathrm{CO}_{2}$ & - & 5.636 & 8.428 & 6.420 & 6.102 \\
\hline & $\mathrm{H}_{2} \mathrm{O}(\mathrm{l})$ & $\geqq 50[6]$ & $\begin{array}{c}56.20 \\
(54.164)\end{array}$ & $\begin{array}{c}57.39 \\
(54.454)\end{array}$ & $\begin{array}{c}53.76 \\
(55.59)\end{array}$ & $\begin{array}{c}55.96 \\
(51.76)\end{array}$ \\
\hline & $\mathrm{N}_{2}$ & - & 37.69 & 33.67 & 39.35 & 37.46 \\
\hline & $\mathrm{KOH}(\mathrm{s})$ & - & 0.029 & 0.024 & 0.270 & 0.028 \\
\hline & $\mathrm{K}_{2} \mathrm{CO}_{3}(\mathrm{~s})$ & - & 0.444 & 0.493 & 0.439 & 0.450 \\
\hline \multirow{2}{*}{$\begin{array}{l}\text { Generated } \\
\text { products } \\
\text { [wt.\%] }\end{array}$} & $\mathrm{KOH}(\mathrm{s})$ & - & 0.065 & 0.068 & 0.056 & 0.062 \\
\hline & $\mathrm{K}_{2} \mathrm{CO}_{3}(\mathrm{~s})$ & - & 2.600 & 2.581 & 2.817 & 2.514 \\
\hline \multicolumn{2}{|c|}{$\begin{array}{l}\text { Number of moles of } \\
\text { generated gas per } 100 \mathrm{~g} \\
\text { of gas-generating agent, } \\
{\left[\mathrm{mol} \cdot(100 \mathrm{~g})^{-1}\right]}\end{array}$} & $<2.70[5]$ & $\begin{array}{c}4.165 \\
(3.9274)\end{array}$ & $\begin{array}{c}4.183 \\
(3.9483)\end{array}$ & $\begin{array}{c}4.115 \\
(3.855)\end{array}$ & $\begin{array}{c}4.120 \\
(3.889)\end{array}$ \\
\hline \multicolumn{2}{|c|}{$\begin{array}{l}\text { Calorific value per mole of } \\
\text { generated gas } \\
{\left[\mathrm{kJ} \cdot \mathrm{mol}^{-1}\right]}\end{array}$} & $95-105$ [5] & $\begin{array}{l}91.23 \\
(96.63)\end{array}$ & $\begin{array}{l}90.80 \\
(96.09)\end{array}$ & $\begin{array}{c}94.38 \\
(100.78)\end{array}$ & $\begin{array}{r}92.59 \\
(98.02) \\
\end{array}$ \\
\hline \multicolumn{2}{|c|}{$\begin{array}{l}\text { Wt.\% of solid products } \\
\text { [wt.\%] }\end{array}$} & $\geqq 10[2]$ & $\begin{array}{c}2.665 \\
(7.733)\end{array}$ & $\begin{array}{c}2.649 \\
(7.687)\end{array}$ & $\begin{array}{c}2.873 \\
(8.374)\end{array}$ & $\begin{array}{c}2.576 \\
(7.463)\end{array}$ \\
\hline \multicolumn{2}{|c|}{$\begin{array}{l}\text { Efficiency of gas evolution } \\
{[\%]}\end{array}$} & $\leqq 90[2]$ & $\begin{array}{c}99.52 \\
(98.64)\end{array}$ & $\begin{array}{c}99.53 \\
(98.65)\end{array}$ & $\begin{array}{c}99.48 \\
(98.51)\end{array}$ & $\begin{array}{c}99.53 \\
(98.67) \\
\end{array}$ \\
\hline \multicolumn{2}{|c|}{$\begin{array}{l}\text { Heat of formation of } \\
\text { teterazole, }\left[\mathrm{kJ} \cdot \mathrm{mol}^{-1}\right]\end{array}$} & $=$ & 782.1 & 422.0 & 235.8 & 238.5 \\
\hline \multicolumn{2}{|c|}{$\begin{array}{l}\text { Nitrogen content of } \\
\text { tetrazole, }[\mathrm{wt} . \%]\end{array}$} & $=$ & 80.22 & 81.36 & 66.64 & 82.33 \\
\hline
\end{tabular}

(s): solid, (1): liquid, ( ): replacing $10 \mathrm{wt} . \%$ of SrN for PSAN. 
It was found that the generated gaseous products were harmless $\mathrm{CO}_{2}, \mathrm{H}_{2} \mathrm{O}$, and $\mathrm{N}_{2}$ for each mixture. The molar percentage of $\mathrm{H}_{2} \mathrm{O}$ for each mixture was slightly higher than the acceptable value of 50 [6], which could be improved upon by replacing PSAN with other oxidizers that produce less water. The calorific value per gram of each mixture was lower than the desirable value of $4000 \mathrm{~J} \cdot \mathrm{g}^{-1}$. The $T_{\mathrm{f}}$ for each mixture was higher than the desirable value of $2273 \mathrm{~K}$. The calculation was also conducted on each mixture by replacing $10 \mathrm{wt} . \%$ of $\mathrm{SrN}$ for PSAN.

The following was inferred based on the results shown in Table 3. The efficiency of gas evolution for each mixture was higher than the desirable value of $90 \%$. The wt. $\%$ of solid products for each mixture was less than the desirable 10. The number of moles of generated gas per $100 \mathrm{~g}$ of each mixture was higher than the desirable value of $2.70 \mathrm{~mol} \cdot\left(100 \mathrm{~g}^{-1}\right)$. The calorific value per mole of generated gas for each mixture was lower than the desirable value of $95 \mathrm{~J} \cdot \mathrm{mol}^{-1}$. It was found that the calculated results for each mixture were generally acceptable for a practical gas-generating agent. Replacing $10 \mathrm{wt} . \%$ of $\mathrm{SrN}$ for PSAN improves the calorific value per mole of generated gas but does not satisfy the recommended values for $T_{\mathrm{f}}$ and mol.\% of $\mathrm{H}_{2} \mathrm{O}$.

\subsection{Sensitivity}

Each tetrazole/PSAN mixture did not ignite even at the limiting impact energy of $49 \mathrm{~J}$ in the $5 \mathrm{~kg}$ drop hammer test or at $353 \mathrm{~N}$ in the friction test. These mixtures can be treated as insensitive mixtures.

\section{Conclusions}

The following conclusions were obtained for the tetrazole/PSAN mixtures:

1) The burning rate of each mixture (except for BHT· $2 \mathrm{NH}_{3} / \mathrm{PSAN}$ ) at $7 \mathrm{MPa}$ was lower than the desirable $10 \mathrm{~mm} \cdot \mathrm{s}^{-1}$ but close to that of GN/SrN/BCN / $56.05 / 19.45 / 24.50$ (a gas-generating agent used in practical applications).

2) The pressure increase rates of the 5-ATZ/PSAN and AGAT/PSAN mixtures were almost the same as that of the GN/SrN/BCN mixture.

3) Based on the chemical equilibrium calculations, these gas-generating agents generated harmless gases. The efficiency of gas evolution, the wt. $\%$ of solid products, and the number of moles per $100 \mathrm{~g}$ of gas-generating agent, were better than the desirable values. However, the $T_{\mathrm{f}}$ and mol. $\%$ of $\mathrm{H}_{2} \mathrm{O}$ were higher and the calorific value per mole of generated gases was lower than the desirable values. 
4) Each mixture was found to be insensitive from the drop hammer and friction tests.

\section{Symbols and Abbreviations}

$a$ : Constant that depends on the chemical composition and initial temperature of the energetic material

$n$ : Pressure exponent of the burning rate

$P$ : Average internal pressure

$r$ : Burning rate

$T_{\mathrm{i}}$ : Initial temperature

AGAT: Aminoguanidinium 5,5'-azobis-1H-tetrazolate

AN: Ammonium nitrate

5-ATZ: 5-Amino-1H-tetrazole

BCN: Copper nitrate basic

BHT $2 \mathrm{NH}_{3}$ : Di-ammonia-5,5-bi-tetrazolate

GN: Guanidinium nitrate

$\mathrm{KN}$ : Potassium nitrate

M5T: 5-Methyl-1H-tetrazole

PSAN: Phase-stabilized ammonium nitrate 5 wt.\% of KN

SrN: Strontium nitrate

$\triangle P:$ Net pressure increase

$\Delta P / \Delta t:$ Rate of pressure increase

$\Delta t$ : Time duration from the onset of pressure increase to the time when the pressure reaches the maximum pressure

\section{References}

[1] Yosida T., Hasegawa T., Application of Reactive Chemicals - From Fireworks to Air Bags and Rocket, Tokyo Progress System LTD (in Japanese), Tokyo, 1996, pp. 12-18.

[2] Khandhadia P.S., Burns S.P., Thermally Stable Nonazide Automotive Airbag Propellants, US Patent 6306232 B1, 2001.

[3] Kubota N., Propellants and Explosives - Thermochemical Aspects of Combustion, WILEY-VCH, Weinheim, 2002, pp.53-54; ISBN 3-527-30210-7.

[4] Burns S.P., Khandhadia P.S., Smokeless Gas Generant Compositions, US Patent 6074 502, 2000.

[5] Sato E., Kubo D., Ikeda K., Gas-generating Agent Composition and Gas Generator Employing the Same, US Patent 6958100 B2, 2005.

[6] Harada T., Ammonium Nitrate Based Gas Generating Composition (in Japanese), Explosion, 2003, 13(3), 128-133. 
[7] Katsuda N., Yabuta M., Wu J., Inflator for an Air Bag, US Patent 6854395 B2, 2005.

[8] Oommen C., Jain S.R., Ammonium Nitrate: a Promising Rocket Propellant Oxidizer, J. Hazard. Mater., 1999, A67, 253-281.

[9] Kim J., Preparation of Phase Stabilized Ammonium Nitrate (PSAN) by a Salting Out Process, J. Chem. Eng. Japan, 1997, 30(2), 336-338.

[10] Cady H.H., The Ammonium Nitrate - Potassium Nitrate System, Propellants Explos. Pyrotech., 1981, 6(2), 49-54.

[11] Wu H.B., Chan C.K., Effects of Potassium Nitrate on the Solid Phase Transitions of Ammonium Nitrate Particles, Atmos. Environ., 2008, 42(2), 313-322.

[12] Sudhakar A.O.R., Mathew S., Thermal Behaviour of CuO Doped Phase-stabilised Ammonium Nitrate, Thermochim. Acta, 2006, 451(1-2), 5-9.

[13] Mathew S., Eisenreich N., Engel W., Thermal Analysis Using X-ray Diffractometry for the Investigation of the Solid State Reaction of Ammonium Nitrate and Copper Oxide, Thermochim. Acta, 1995, 269/270, 475-489.

[14] Mebrotra A.K., Markovich I.L., Potassium Fluoride Stabilized Ammonium Nitrate and Method of Producing Potassium Fluoride Stabilized Ammonium Nitrate, US Patent 5098 683, 1992.

[15] Golovina N., Nechiporenko G., Nemtsev G., Zyuzin I., Manelis G.B., Lempert D., Ammonium Nitrate Phase State Stabilization with Small Amounts of Some Organic Compounds, Cent. Eur. J. Energ. Mater., 2009, 6(1), 45-56.

[16] Hasue K., Yoshitake K., The Mixture of the Phase Stabilized Ammonium Nitrate Containing Potassium Nitrate and $1 \mathrm{HT}$ as the New Gas Generant Composition, Sci. Technol. Energ. Mater, 2013, 74(3), 66-72.

[17] Hasue K., Akanuma T., Hodai H., Date S., Combustion Aspects of the Consolidated Mixtures of 5-Amino-1H-tetrazole and Potassium Perchlorate (in Japanese), Kayaku Gakkaishi (Sci. Technol. Energ. Mater.), 1999, 60(1), 31-37.

[18] Miyata Y., Kanou H., Date S., Hasue K., Combustion Characteristics of the Consolidated Mixtures of 5-Amino-1H-tetrazole and Sodium Perchlorate, Sci. Technol. Energ. Mater, 2005, 66(1), 233-239.

[19] Miyata Y., Date S., Hasue K., Effect of Additional Copper(II) Oxide on the Combustion of 5-Amino-1H-tetrazole and Lithium Perchlorate Mixtures (I) Examination of the Burning Mechanism, Sci. Technol. Energ. Mater, 2007, 68(5), 125-130.

[20] Hasue K., Boonyarat P., Miyata Y., Takagi J., Combustion Characteristics of 5-Amino-1H-tetrazole and Strontium Nitrate Mixtures (in Japanese), Kayaku Gakkaishi (Sci. Technol. Energ. Mater.), 2001, 62(4), 168-174.

[21] Miyata Y., Date S., Hasue K., Combustion Mechanism of Consolidated Mixtures of 5-Amino-1H-tetrazole with Potassium Nitrate or Sodium Nitrate, Propellants Explos. Pyrotech., 2004, 29(4), 247-252.

[22] Iwakuma K., Miyata Y., Date S., Kohga M., Hasue K., A Study on the Combustion of 5,5'-Azobis-tetrazole aminoguanidine / Strontium Nitrate as a Gas Generating Agent, Sci. Technol. Energ. Mater., 2007, 68(4), 95-101. 
[23] Onishi A., Tanaka H., Method of Tetrazole Amine Salts Having Improved Physical Properties for Generating Gas in Airbags, US Patent 5439 251, 1995.

[24] Abe M., Ogura T., Miyata Y., Okamoto K., Date S., Kohga M., Hasue K., Evaluation of Gas Generating Ability of Some Tetrazoles and Copper(II) Oxide Mixtures Through Closed Vessel Test and Theoretical Calculation, Sci. Technol. Energ. Mater, 2008, 69(6), 183-190.

[25] Miyata Y., Abe M., Date S., Kohga M., Hasue K., Burning Characteristics of Aminoguanidinium 5,5' -azobis-1 H-tetrazolate/Ammonium Nitrate as Gas Generating Mixtures, Sci. Technol. Energ. Mater., 2008, 69(4), 117-123.

[26] Miyata Y., Hasue K., Effect of Initial Temperature and Pressure on the Burning Rate of AGAT/AN Mixtures, J. Energ. Mater., 2011, 29(1), 26-45.

[27] Miyata Y., Hasue K., Burning Characteristics of Aminoguanidinium 5,5'-Azobis1H-tetrazolate /Ammonium Nitrate Mixture - Effects of Particle Size and Composition Ratio on Burning Rate, J. Energ. Mater., 2011, 29(4), 344-359.

[28] Yositake K., Ihoh K., Date S., Hasue K., Effect of Initial Temperature on the Burning Rate of Some Mixtures of Tetrazoles and Nitrates, Int. Pyrotechnics Seminar, Proc., 36th, Rotterdam, 2009, 287-301.

[29] Hasue K., Yoshitake K., Equation of Burning Rate as a Function of Pressure and Temperature for 1H-Tetrazole/Ammonim Nitrate Mixtures, J. Energ. Mater., 2013, 31(4), 251-260.

[30] Hasue K., A Burning Rate Equation as a Function of Pressure and Temperature for a BTA $\cdot \mathrm{NH}_{3} / \mathrm{PSAN}$ Mixture, J. Energ. Mater., 2014, 32(3), 199-206.

[31] Volk F., Bathelt H., User's Manual for the ICT-Thermodynamic Code, FraunhoferInstitut für Chemische Technologie, Pfinztal, 1998.

[32] Industrial Explosives Society Standard, Industrial Explosives Society, Tokyo, 1986, pp. 26-37.

[33] Khandhadia P.S., Burns S.P., Williams G.K., High Gas Yield Non-azide Gas Generants, US Patent 6210505 B1, 2001. 